was added after 24 hours all but one were sterile. The findings in cultures for anaerobes were similar. In a separate study Shanson showed that blood concentrations of amoxycillin were higher and much better sustained than those of penicillin V. This should surprise no one; not only is penicillin $\mathrm{V}$ incompletely absorbed, but much of what is absorbed is degraded to penicilloic acid, so that no more than a third of the dose circulates in active form. ${ }^{9}$ Amoxycillin suffers from no such defects, and may therefore be the better oral prophylactic, certainly deserving a place in any future trials.

Petersdorf's paper concludes with a plea that the medical and dental professions should keep much better records. No statistical proof exists of the efficacy of any of these procedures, and we agree that if we are to rely so much on oral antibiotics we should obtain such proof.

American Heart Association, Circulation, 1977, 56, 139A

2 Ashby, E C, Rees, M, and Dowding, C H, British Medical fournal, 1978, $2,1263$.

3 British Medical fournal, 1977, 2, 1564

4 Petersdorf, R G, American fournal of Medicine, 1978, 65, 22.

5 Durack, D T, and Petersdorf, R G, Fournal of Clinical Investigation, 1973, 52, 592.

'Pelletier, LL, jr, Durack, D T, and Petersdorf, R G, fournal of Clinical Investigation, 1975, 56, 319.

Kaye, D, Infective Endocarditis. Baltimore, University Park Press, 1976.

${ }^{8}$ Shanson, D C, Cannon, P, and Wilks, M, fournal of Antimicrobial Chemotherapy, 1978, 4, 431.

${ }^{9}$ Hellström, K, Rosen, A, and Swahn, $\AA$, Clinical Pharmacology and Therapeutics, 1974, 16, 826 .

\section{Polycystic disease of the kidneys}

Two main types of bilateral polycystic disease have been recognised: the infantile and the adult (the multiple renal cysts associated with certain syndromes of multiple congenital malformations and chromosomal abnormalities ${ }^{1}$ are very rare). The infantile type is usually fatal in infancy, often soon after birth; it also is associated with cystic malformations of the intrahepatic bile ducts, with apparently autosomal recessive inheritance, whereas the adult type is inherited as an autosomal dominant. But this now seems to be too simple a picture of the range of polycystic kidney disease.

Typically, the adult type presents in the fourth or fifth decade, and clinical features may include recurrent macroscopic haematuria; loin pain, due to infection or haemorrhage into cysts; clot colic; hypertension; and swelling of the abdomen due to the enlarging kidneys, which seem also to be more vulnerable to trauma from accidents. This type of the disease is associated with intracranial aneurysms and sometimes hyperuricaemia. Solitary or multiple cysts may also occur in the liver and occasionally in other organs such as the pancreas and spleen. ${ }^{2}$ The liver cysts do not result in cirrhosis or portal hypertension, but occasionally they become infected or painful because of haemorrhage into them. In the past patients usually died from complications associated with hypertension, subarachnoid haemorrhage after rupture of an intracranial aneurysm, or renal failure. The adult type of polycystic disease is an important cause of severe chronic renal failure, and is the primary underlying renal disease in about $8 \%$ (3978) of the 47741 adult patients in the European Dialysis and Transplantation Registry. ${ }^{3}$ It may, however, remain subclinical, being observed for the first time at necropsy in elderly patients dying from other causes. Now that even the badly affected patients often survive for a long time, thanks to maintenance haemodialysis and renal transplantation, adequate genetic counselling is essential.

Bilateral polycystic disease in infancy and childhood is now seen to have a wider clinical range than was at first thought, and may consist of several different entities. Blyth and Ockenden described four groups-perinatal, neonatal, infantile, and juvenile. ${ }^{4}$ The perinatal group presented with huge kidneys at birth, the baby being stillborn or dying within a few weeks from renal failure. In this group $90 \%$ of the renal tubules were affected and hepatic fibrosis was minimal. The neonatal group presented in the first month with large kidneys and died in the first year of uraemia; $60 \%$ of the renal tubules were affected and hepatic fibrosis was minimal. The infantile group presented at 3-6 months with large kidneys and hepatosplenomegaly, dying in childhood with systemic and portal hypertension and progressive renal failure; a quarter of the renal tubules were affected and there was considerable hepatic fibrosis. Finally, the juvenile group developed the disease in childhood, with hepatosplenomegaly and progressive portal hypertension, and most survived into their teens; here less than $10 \%$ of the renal tubules were affected, but gross hepatic fibrosis was present. Family studies suggested but did not prove that all four groups represented different autosomal recessive conditions, though other workers have considered that the difference between the groups may reflect differences in the natural history of the disorder rather than separate entities. ${ }^{5}$ Congenital hepatic fibrosis, however, is probably a separate entity. ${ }^{56}$

Blyth and Ockenden also reported for the first time cases of the adult type of polycystic kidney disease presenting in childhood. Dominant inheritance was clear in two of the patients. Since then several other probable or possible cases have come to light. ${ }^{7-10}$ Recently Shokeir has described a further six examples. ${ }^{11}$ The six infants were unrelated, and at diagnosis one was a stillborn fetus, one a liveborn baby immediately after birth, and one a neonate of 3 weeks, and three were infants ranging from $2 \frac{1}{2}$ to 4 months. The five liveborn babies died hours to weeks after the diagnosis. Other cases of the adult type were then found in the families, and in four cases parents turned out to have the disease. The disorder was transmitted as an autosomal dominant. The diagnosis in parents or other members of the family, however, was made only because the suspicion of "adult" polycystic disease in the offspring led to a specific search for it.

The adult type may be recognised in infancy during radiological investigation or on gross pathological examination: the intravenous urogram characteristically shows stretching and distortion of the caliceal system, while pathological examination shows cysts, from microscopic to gross, in both cortex and medulla with intervening areas containing normal renal tissue. In the infantile type, on the other hand, the cysts (which correspond to the type I of Osathanondh and Potter ${ }^{12}$ ) are fusiform and arranged radially throughout the kidney fairly uniformly, and this may be recognised radiologically and on gross pathological examination. Histological examination of the liver may help to differentiate the infantile from the adult type, since the characteristic intrahepatic biliary malformations are always present in the portal tracts of those with the infantile type. When there is a strong suspicion of the adult type of polycystic disease in infancy the parents and other members of the family should be investigated even if there is no history of the disease. Genetic predictions should not be based on the autosomal recessive inheritance characteristic of infantile polycystic kidney disease until autosomal dominant inheritance of "adult" polycystic kidney disease has been excluded. 
Are all the forms of polycystic kidney disease really due to developmental abnormalities? Previously even the adult type has been attributed to abnormal fetal development ${ }^{12}$; but experimentally, diphenylamine, ${ }^{13} 14$ long-acting adrenal corticosteroids, ${ }^{15}$ and potassium depletion ${ }^{16}$ can all produce cystic disease of the kidneys. Possibly adults who develop polycystic disease have inherited simply a metabolic defect that leads to secondary changes in the kidneys with the formation of cysts. ${ }^{17}$

${ }^{1}$ Bernstein, J, in Birth Defects, Original Article Series, vol 6 No 3, ed D Bergsma, p 9. New York, National Foundation, 1970.

${ }^{2}$ Dalgaard, O Z, Acta Medica Scandinavica, 1957, suppl 328.

3 Jacobs, C, et al, Proceedings of the European Dialysis and Transplant Association, 1977, 14, 3.

${ }^{4}$ Blyth, H, and Ockenden, B G, Fournal of Medical Genetics, 1971, 8, 257.

${ }^{5}$ Lieberman, E, et al, Medicine, 1971, 50, 277.

${ }^{6}$ Kerr, D N S, Warrick, C K, and Hart-Mercer, J, Clinical Radiology, 1962, 13, 85.

7 Mehrizi, A, et al, Bulletin of the Fohns Hopkins Hospital, 1964, 115, 92.

${ }^{8}$ Kaye, C, and Lewy, P R, Fournal of Pediatrics, 1974, 85, 807.

${ }^{9}$ Begleiter, M, Smith, T H, and Harris, D J, Lancet, 1977, 2, 1073.

10 Fellows, R A, et al, Pediatric Radiology, 1976, 4, 87.

${ }^{11}$ Shokeir, M H K, Clinical Genetics, 1978, 14, 61 .

12 Osathanondh, V, and Potter, E L, Archives of Pathology, 1964, 77, 485.

13 Thomas, J O, Cox, A J, and Deeds, F, Stanford Medical Bulletin, 1957, 15, 90.

14 Safouh, M, Crocker, J F S, and Vernier, R L, Laboratory Investigation, $1970,23,392$.

15 Perey, D Y, Herdman, R C, and Good, R A, Science, 1967, 158, 494.

${ }^{16}$ Crocker, J F S, and Vernier, R L, Science, 1970, 169, 485.

${ }^{17}$ Darmady, E M, Offer, J, and Woodhouse, M A, Lancet, 1970, 1, 547.

\section{Amputation of the ischaemic $\operatorname{limb}$}

In spite of the best efforts of modern vascular surgery and the increasing use of reconstructive "limb salvage" procedures, many patients with ischaemic legs eventually have to have them amputated. When choosing the level at which to amputate the surgeon faces conflicting objectives. Amputations through the thigh heal well, but the mortality rate is between $10 \%$ and $40 \%,{ }^{2}$ and of those patients who survive the operation only about a third will ever become mobile on a prosthesis. ${ }^{3}$ By contrast, the patient whose leg has been amputated below the knee has twice as good a prospect of successful mobilisationbut he runs a greater risk that the amputation will not heal. Revision of a failed amputation not only subjects the patient to the risks of another operation but may be disastrous for his morale.

It is crucial, therefore, that the correct judgment is made when choosing the level of amputation. The decision is usually taken on clinical grounds supplemented by information from current or previous arteriography. The clinical assessment takes into account not only the extent of the ischaemia in the leg to be amputated but also the state of the patient's other leg, his general health, and his mobility. To supplement this clinical assessment surgeons badly need a reliable and objective means of judging whether healing is likely at the chosen level. Measuring the distal arterial pressure by doppler ultrasound, ${ }^{4}$ testing skin blood flow ${ }^{5}$ and pressure ${ }^{6}$ and muscle $\mathrm{pH}^{7}$ and other investigations have all been tried but they have proved only marginal improvements on clinical judgment.

Amputation below the calf is indicated only very rarely when the vessels of the limb are diffusely affected by athero- sclerosis. Most surgeons prefer below-knee amputation with a long posterior flap; and where it has failed-or is expected to fail - the most likely alternative is a myoplastic, through-thigh amputation. In Britain these two operations account for around $95 \%$ of vascular amputations. What, then, is the place of the through-knee amputation and its near relative the GrittiStokes amputation?

In theory, amputation at the knee has much to recommend it. Disarticulation-amputation is less traumatic for the patient and has a mortality rate comparable with that of the belowknee operation ${ }^{8}$; it yields a tough end-bearing stump whose bulbous shape fits snugly into the prosthesis; and the incidence of both phantom pains and flexion and abduction contractures is said to be less. Retaining the full length of the femur together with its muscles provides an excellent lever of great value to the bed-bound patient. A recent report ${ }^{9}$ has confirmed the virtues of the operation in orthopaedic practice, but it has a reputation for poor healing when used for patients with vascular disease. Yet in reported series ${ }^{1011}$ over $80 \%$ of wounds healed satisfactorily, and the use of equal or lateral flaps might improve this rate further. Prostheses for this stump used to be ungainly, but this objection has been largely overcome in modern appliances. The most cogent argument against the through-knee operation is that any amputation which preserves the knee joint is better than one which does not, even if the below-knee stump is short. When a through-knee amputation is being considered, a high below-knee operation may also be feasible.

The Gritti-Stokes amputation, in which the femoral condyles are sawn off and the patella fixed on to the cut end of the femur, is another possibility. The procedure has been criticised for a high incidence of stump pain and problems due to failure of union between the patella and the femur. Nevertheless, a recent series from Nottingham ${ }^{12}$ failed to confirm these objections and suggested that good results are possible with careful patient selection.

Half of all unilateral amputees who survive for three years lose the other leg, and a patient with bilateral through-thigh amputations has great difficulty moving about in bed. With even one through-knee or Gritti-Stokes stump his mobility is improved, so surgeons need to make every effort to retain as much femur as possible when the knee joint cannot be preserved. Whenever a below-knee amputation seems unlikely to heal then there is a strong case for considering, as an alternative to an amputation through the thigh, either a GrittiStokes or through-knee amputation.

${ }^{1}$ Gilchrist, A R, Fournal of the Royal College of Surgeons of Edinburgh, 1961, 6, 159 .

2 Warren, R, and Record, E, Lower Extremity Amputations for Arterial Insufficiency. Boston, Little Brown, 1967.

${ }^{3}$ Couch, N P, et al, American fournal of Surgery, 1977, 133, 469.

${ }^{4}$ Barnes, R W, Shanik, G D, and Slaymaker, R N, Surgery, 1976, 79, 13.

5 Holloway, G A, and Burgess, E M, Surgery, Gynecology, and Obstetrics, 1978, 146, 750 .

${ }^{6}$ Chavatzas, D, and Jamieson, C W, Lancet, 1974, 1, 711.

7 Young, A E, Henderson, B A, and Couch, N P, Surgery, Gynecology, and Obstetrics, 1978, 146, 533.

${ }^{8}$ Chilvers, A S, et al, British fournal of Surgery, 1971, 58, 824.

${ }^{9}$ Mazet, R, Schmitter, M D, and Chupurdia, R, fournal of Bone and foint Surgery, 1978, 60A, 675.

${ }^{10}$ Howard, R R S, Chamberlain, J, and Macpherson, A I S, Lancet, 1969, 2, 240.

11 Newcombe, J F, and Marcuson, R W, British fournal of Surgery, 1972, 59, 260.

12 Doran, J, Hopkinson, B R, and Makin, G S, British fournal of Surgery, 1978, 65, 135. 